\title{
Sequential Nitrogen Ion Implantation in Si-Based GaAs Matrix and Subsequent Thermal Annealing Process: Electrical Characterization
}

\author{
NAND LAL SHARMA ${ }^{1}$, SARAVANAN RAJAMANI ${ }^{1}$, VLADIMIR SHENGUROV ${ }^{2}$, NIKOLAY BAIDUS $^{2}$, \\ DMITRY KOROLEV ${ }^{2}$, ALYONA NIKOLSKAYA ${ }^{2}$, ALEXEY MIKHAYLOV ${ }^{2}$, DAVID TETELBAUM ${ }^{2}$ \\ and MAHESH KUMAR ${ }^{1, *}$ \\ ${ }^{1}$ Department of Electrical Engineering, Indian Institute of Technology, Jodhpur 342 037, India \\ ${ }^{2}$ Lobachevsky University, Nizhny Novgorod, Russia
}

(Received on 21 March 2018; Accepted on 15 September 2018)

\begin{abstract}
The ion implantation is well-established techniques for device fabrication in III-V semiconductors. GaAs is grown on Silicon ( $\mathrm{Si}$ ) substrate using Germanium $(\mathrm{Ge})$ as a buffer layer to reduce the lattice mismatch. The implantation of nitrogen ions in GaAs layers of the epitaxial-grown structure $\mathrm{GaAs} / \mathrm{Ge} / \mathrm{Si}$ is done with sequential implantation of doses from $0.8 \mathrm{x}$ $10^{17}$ to $2.0 \times 10^{17} \mathrm{~cm}^{-2}$ with respective energies ranging from $40 \mathrm{keV}$ to $120 \mathrm{keV}$ per atomic ion. This was aimed to achieve more uniform depth distribution of nitrogen as a result of multiple ion implantation. A subsequent high temperature annealing is done for nanostructures formation and to improve the crystal quality. For the annealing process, rapid thermal annealing (RTA) and furnace annealing (FA) are used in temperature range of $700^{\circ} \mathrm{C}-850^{\circ} \mathrm{C}$ under argon and nitrogen environment. Current-voltage (I-V) characterization are carried out to study the effect of the post-annealing process on the barrier height and ideality factor. The electrical parameters are observed to have a strong dependence on temperature. The inhomogeneity in barrier height gives rise to the temperature dependence of barrier height.
\end{abstract}

Keywords: Gallium Arsenide; Ion Implantation; Annealing; Optical Lithography; Barrier Height

\section{Introduction}

The direct ion implantation technique is widely used to modify optical and electrical properties of III-V based compound semiconductors (Pearton 1990). The requirement of precise doping profile, distribution of implanted species and reproducibility makes the ion implantation a standard non-destructive process (He et al., 1991). Nowadays nanostructures are going under extensive research by several groups in order to use them in several optoelectronic applications. Semiconductor nanostructures can be grown on various substrates by several techniques such as molecular beam epitaxy, metalorganic chemical vapour deposition and chemical routes. Gallium nitride $(\mathrm{GaN})$ is used for a wide range of applications like light emitting diodes, laser, and power electronics devices due to its excellent optoelectronic properties (Nakamura et al., 1996; Morkoc et al.). However, the growth of $\mathrm{GaN}$ and gallium arsenide ( $\mathrm{GaAs})$ is still a difficult task due to their lattice and thermal expansion coefficient mismatch with CMOS compatible materials like Si (Kroemer 1986). The fabrication of nanostructures embedded in a GaAs matrix is quite interesting for realizing the modern devices due to high mobility and the direct bandgap of GaAs, but it is a challenging task. Ion implantation is an appropriate method by which the embedded nanostructures can be formed inside the matrix (Lin et al., 1995 and Wolk et al., 1997). Ion implantation technique is also compatible with semiconductor nanotechnology and can be used to modify optical and electrical characteristics of semiconductor materials. Unlike the conventional thin films or nanocrystals on a substrate, this method provides encapsulation and passivation, as the nanocrystals are formed directly in a substrate matrix. Another advantage of this technique is the ability to control the concentration, size and localization of the implanted

*Authorfor Correspondence: E-mail:mkumar@iitj.ac.in 
species, which allows tailoring optical, electrical and magnetic properties.

The ion-implantation in the GaAs matrix have been carried out by many researchers to modify their optical and electrical properties. The $\mathrm{N}$ ion implantation in the GaAs matrix is the most suitable process to form GaN based nanostructures for high temperature and high-power devices due to their excellent thermal stability. The device based on ionsynthesized nanostructures provides an innovative approach for realizing photodetectors (Koo et al., 2006; Rajamani et al., 2018). In the GaAs matrix, the direct bandgap and high mobility allow producing integrated optoelectronic devices. Although there is very large mismatch between lattice constant of GaAs and $\mathrm{GaN}$ (20\%), it has been found that the GaN nanostructures could be formed in GaAs matrix by implantation of $\mathrm{N}_{1}^{+}, \mathrm{N}_{2}^{+}$ions and thermal annealing (De Luise, 1993; Lin et al., 1995; Wolk et al., 1997; Amine et al., 2002; Weng et al., 2005a). In such cases, high temperature annealing enhances the exchange interaction between $\mathrm{N}$ and $\mathrm{As}$ atoms in the GaAs matrix which is thermodynamically favourable (Lin et al., 1995; Amine et al., 2002). Also, we know that As is more volatile than $\mathrm{Ga}$ which also facilitates the As replacement by $\mathrm{N}$ under implantation followed by the annealing process. And the other aspect is that the ion-implantation technique is beyond the solid solubility limits (Lin et al., 1995). The optical studies also reveal the formation of GaN based nanostructures in GaAs matrix by ion implantation (Weng et al., 2002b; Bumai et al., 2005).

In this work, we present the implantation of nitrogen ions in the Si-based GaAs layer obtained by an original approach (Buzynin et al., 2017) that combines different epitaxial techniques to produce high-quality hybrid $\mathrm{Si} / \mathrm{Ge} / \mathrm{GaAs}$ structures to be used instead of GaAs monolithic substrates for fabrication of solar cells, photodetectors, LEDs, lasers, etc. This method of synthesis of GaN nanocrystals in GaAs matrix is of extra interest because, on the one hand, it is compatible with silicon technology and, on the other hand, it provides ample opportunities for advanced micro and optoelectronic devices due to the creation of nano (hetero) compositions from four materials $\mathrm{Si}, \mathrm{Ge}, \mathrm{GaAs}$ and $\mathrm{GaN}$. Compared to the case of ion synthesis of GaN nanocrystals by co-implantation $\left(\mathrm{Ga}^{+}\right.$and $\left.\mathrm{N}^{+}\right)$into $\mathrm{SiO}_{2} / \mathrm{Si}$ (Korolev et al., 2017) the present method is simpler from the technological point of view and excludes the problem of out-diffusion of implanted atoms during annealing (Lin et al., 1995; Amine et al., 2002; Bumai et al., 2005). The I-V characterization is studied to see the effect of ionimplantation in the GaAs matrix in terms of implantation doses and annealing conditions. Figure 1 shows the schematic process of the ion implantation in GaAs and nanostructure formation.

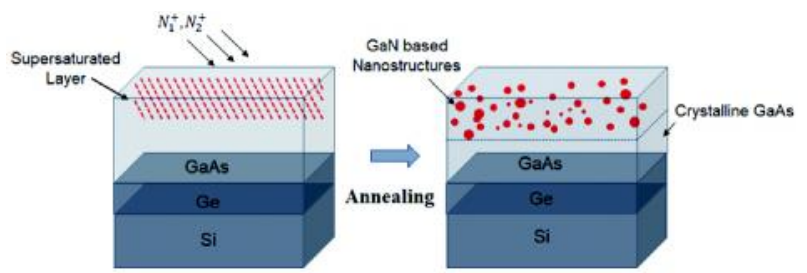

Fig. 1: Schematics of the ion-implantation and nanostructure formation in the Si-based GaAs matrix

\section{Materials and Methods}

After growth of $100 \mathrm{~nm}$ p-Si on $\mathrm{n}-\mathrm{Si}$ substrate by molecular-beam epitaxy, a $600 \mathrm{~nm}$ Ge layer was grown by the hot-wire chemical vapour deposition technique at $300^{\circ} \mathrm{C}$. After that, a $1000 \mathrm{~nm}$ thick GaAs layer was grown by metal-organic chemical vapour deposition. Detailed information about the complete technological route and quality of epitaxial layers can be found elsewhere (Buzynin et al., 2017). A chemical cleaning of $n-\mathrm{Si} / \mathrm{Ge} / \mathrm{GaAs}$ substrate is done prior to the ion implantation. The sequential ion implantation of $\mathrm{N}_{1}^{+}(120 \mathrm{keV}$ and $80 \mathrm{KeV})$ and $\mathrm{N}_{2}{ }^{+}(80 \mathrm{keV})$ was done using ILU-200 (Russia) ion implanter at the pressure lower than $10^{-6}$ Torr in the target chamber (maintained by the oil-free pumping). Molecular $\mathrm{N}_{2}{ }^{+}$ ions were used to reduce the irradiation time: as the $\mathrm{N}_{2}{ }^{+}$molecular ion at the first collision breaks up into two atomic ions with equal energies, such irradiation is equivalent to that of atomic beam with a doubled dose at half the energy. The sequential implantation was performed in order to get more homogeneous depth profile of implanted atoms in GaAs layer according to the SRIM simulation (Fig. 2).

After the implantation, the samples are processed for thermal annealing by rapid thermal annealing (RTA) in an argon atmosphere for $30 \mathrm{sec}$ or furnace annealing (FA) in the nitrogen atmosphere for 15 minutes. The JIPELEC JetFirst 100 system is 


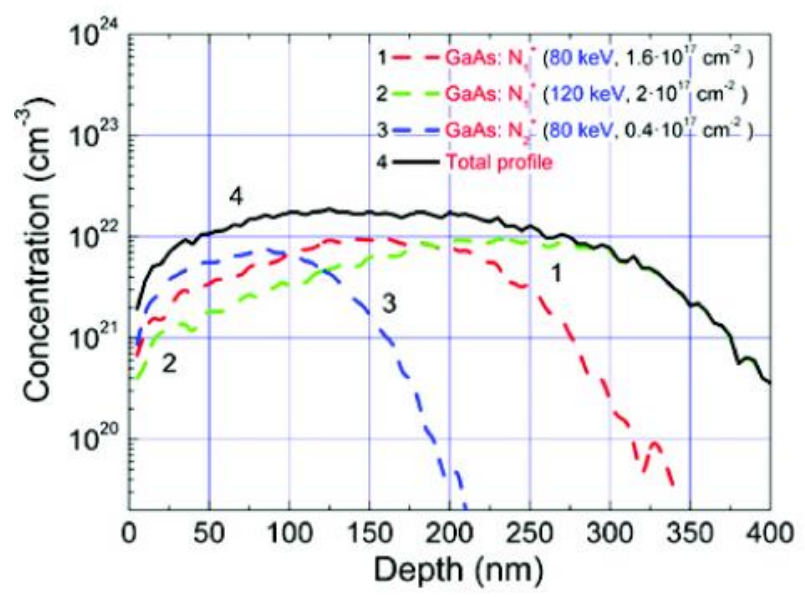

Fig. 2: SRIM-simulated depth profiles of implanted ions

used for RTA treatment. For references, sample series 0 is characterized where only annealing step is done. The sample series 1, where ion implantation and annealing are done, is listed in Table 2 with detailed parameters. The ion beam current density is kept constant at around $7 \mu \mathrm{A} / \mathrm{cm}^{2}$ for sample series 1 . During thermal annealing, a proximity method is used where the implanted side is covered with GaAs wafer to reduce the arsenic evaporation from the surface.

The formation of GaN nanocrystals in ionimplanted samples after RTA and FA is confirmed by the X-ray diffraction (XRD) data obtained for the reference bulk GaAs samples (Fig. 3). According to the physical arguments, one can be aware that these results could be transferred to the samples used for electrical measurements.

The samples were further processed for device fabrication, where $\mathrm{Cr}(10 \mathrm{~nm}) / \mathrm{Au}(200 \mathrm{~nm})$ thin films are deposited by thermal evaporation to fabricate interdigitated electrodes (IDEs). The IDEs are defined using a standard photolithography process. The IDEs forms back to back Schottky contacts. The pattern provides $30 \mu \mathrm{m}$ gapes between the fingers and

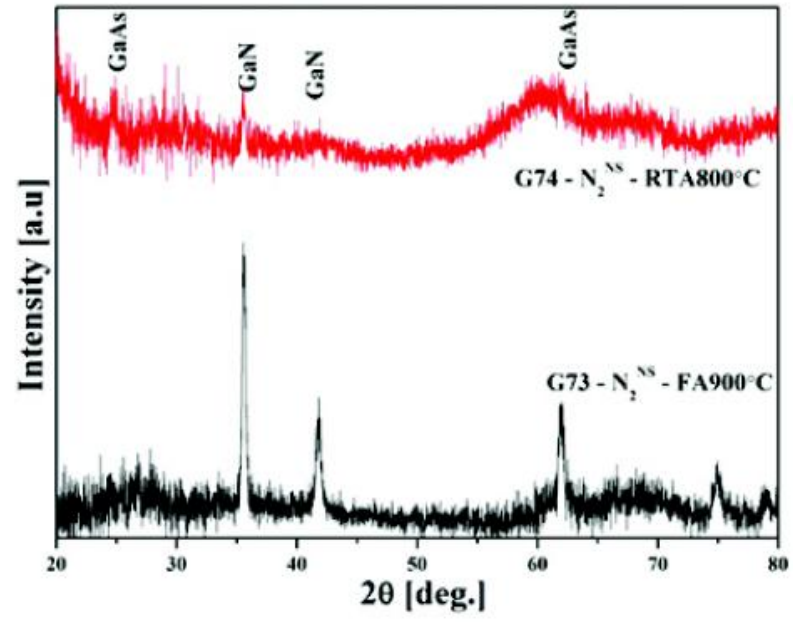

Fig. 3: XRD patterns for the samples of GaAs implanted with $\mathrm{N}_{2}^{+}\left(40 \mathrm{keV}, 2.5^{\prime} \cdot 10^{16} \mathrm{~cm}^{-2}\right)$ and subjected to RTA and FA treatments

Table 1: Details of samples for series 0

\begin{tabular}{lll}
\hline Sample series 0 & Annealing & Time \\
\hline 00 & as grown & - \\
01 & RTA $\left(800^{\circ} \mathrm{C}\right)$ & $30 \mathrm{sec}$ \\
02 & FA $\left(700^{\circ} \mathrm{C}\right)$ & $15 \mathrm{~min}$ \\
03 & FA $\left(800^{\circ} \mathrm{C}\right)$ & $15 \mathrm{~min}$ \\
04 & $\mathrm{FA}\left(850^{\circ} \mathrm{C}\right)$ & $15 \mathrm{~min}$ \\
\hline
\end{tabular}

provides an effective length of electrodes around 1 mm. Figure 4(A-E) shows the schematic representation of the fabrication IDEs of $\mathrm{Cr} / \mathrm{Au}$ on GaAs by thermal deposition and lithography process. Figure 4(F) shows the optical micrograph of IDE. The current-voltage (I-V) characteristic of the structures is measured by Keithley SCS 4200 on a probe station.

\section{Results and Discussion}

The growth of GaAs on Ge is always associated with defects due to lattice mismatch and difference in

Table 2. Details of ion implantation and annealing parameters of samples for series 1

\begin{tabular}{lllll}
\hline Samples series 1 & $\begin{array}{l}\mathrm{N}_{1}{ }^{+}(\mathrm{E}=120 \mathrm{ke} \\
\left.\mathrm{V}, \mathrm{j}=7 \mu \mathrm{A} / \mathrm{cm}^{2}\right)\end{array}$ & $\begin{array}{l}\mathrm{N}_{1}^{+}(\mathrm{E}=80 \mathrm{ke} \\
\left.\mathrm{V}, \mathrm{j}=7 \mu \mathrm{A} / \mathrm{cm}^{2}\right)\end{array}$ & $\begin{array}{l}\mathrm{N}_{2}^{+}(\mathrm{E}=80 \mathrm{ke} \\
\left.\mathrm{V}, \mathrm{j}=7 \mu \mathrm{A} / \mathrm{cm}^{2}\right)\end{array}$ & Annealing \\
\hline 11 & $2 \times 10^{17} \mathrm{~cm}^{-2}$ & $1.6 \times 10^{17} \mathrm{~cm}^{-2}$ & $0.4 \times 10^{17} \mathrm{~cm}^{-2}\left(\right.$ atomic dose $\left.0.8 \times 10^{17} \mathrm{~cm}^{-2}\right)$ & $\mathrm{RTA}\left(800^{\circ} \mathrm{C}, 30 \mathrm{~s}\right)$ \\
12 & $2 \times 10^{17} \mathrm{~cm}^{-2}$ & $1.6 \times 10^{17} \mathrm{~cm}^{-2}$ & $0.4 \times 10^{17} \mathrm{~cm}^{-2}$ & $\mathrm{FA}\left(700^{\circ} \mathrm{C}, 15 \mathrm{~min}\right)$ \\
13 & $2 \times 10^{17} \mathrm{~cm}^{-2}$ & $1.6 \cdot 10^{17} \mathrm{~cm}^{-2}$ & $0.4 \times 10^{17} \mathrm{~cm}^{-2}$ & $\mathrm{FA}\left(800^{\circ} \mathrm{C}, 15 \mathrm{~min}\right)$ \\
14 & $2 \times 10^{17} \mathrm{~cm}^{-2}$ & $1.6 \times 10^{17} \mathrm{~cm}^{-2}$ & $0.4 \times 10^{17} \mathrm{~cm}^{-2}$ & $\mathrm{FA}\left(850^{\circ} \mathrm{C}, 15 \mathrm{~min}\right)$ \\
\hline
\end{tabular}




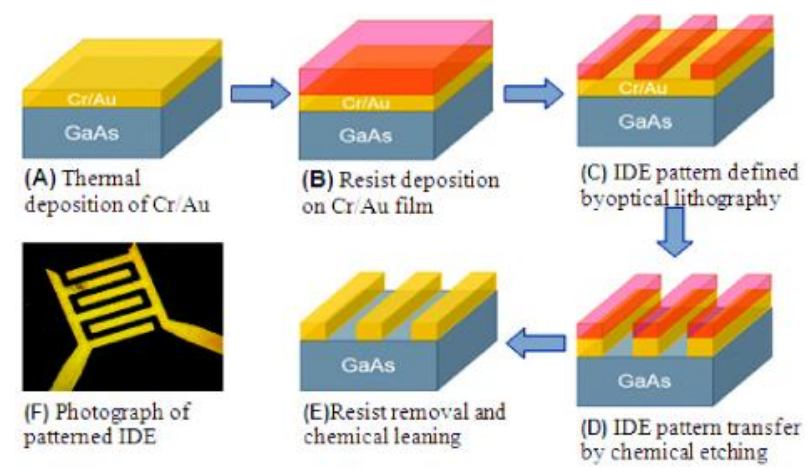

Fig. 4: (A-E) Show the fabrication process of integrated electrodes on the GaAs wafer. (F) shows the optical micrograph of patterned IDE. There is $30 \mu \mathrm{m}$ gap between the IDE fingures

thermal expansion coefficients (Petroff, 1986). The annealing step is mostly used to improve the crystalline quality of the layer after heteroepitaxial growth.

Figure 5(A) shows the current-voltage characteristic of the series- 0 where only annealing step is processed. The nonlinear and symmetric I-V curve suggests the back to back Schottky contacts between GaAs and Au electrodes. Here we observe that the current in the RTA sample (01) increases to three orders of magnitude compared to the as-grown sample (00). The larger value of current in annealed samples is due to the reduction of defect concentration and improvement of crystalline quality of the GaAs layer grown on Ge.

Figure 5(b) shows the I-V characteristics of the

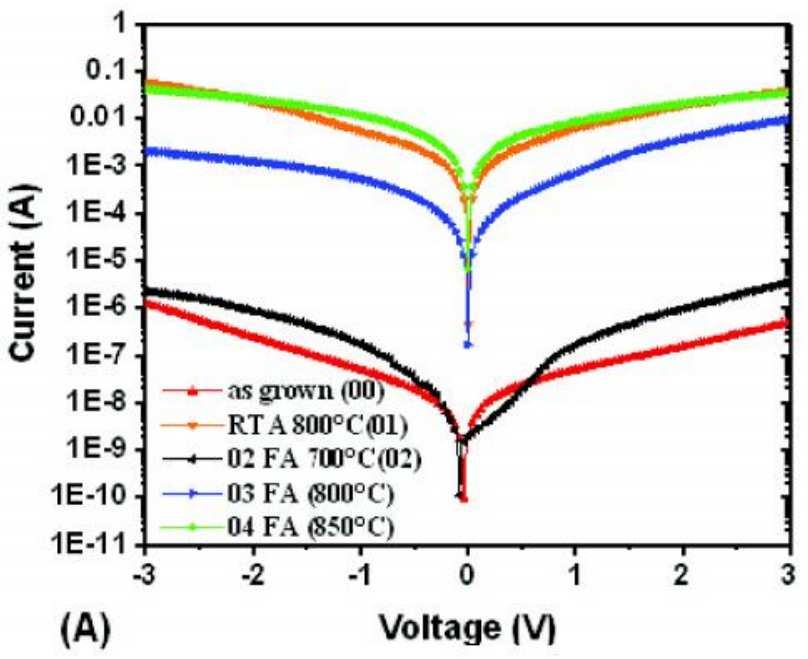

series 1 where nitrogen implantation is followed by annealing step. The lower currents in these samples compared to series 0 is attributed as due to the ionbeam damage of the GaAs matrix, which reduces the concentration and mobility of charge carriers. The incorporation of nitrogen into the GaAs also reduces the mobility of the carriers (Duncan and Matteson, 1984). The other assumption is that the formation of GaN nanocrystals after annealing lowers the carrier mobility in GaAs matrix but do not contribute to the electrical conduction.

The rectifying behaviour of the I-V characteristic for the metal-semiconductor junction is dominated by thermionic emission and is expressed by the following equation (Sze 1981, page 256):

$$
\begin{aligned}
& I=I_{s}\left[\exp \left\{\frac{q V}{\eta k T}\right\}-1\right] \text { with } \\
& I_{s}=A A^{*} T^{2} \exp \left(-\frac{\phi_{b}}{k T}\right),
\end{aligned}
$$

where $I_{s}$ is the saturation current, $\mathrm{q}$ is the elementary charge, $\mathrm{V}$ is the applied voltage, $\eta$ is the ideality factor, $\Phi_{b}$ is the barrier height, $k$ is the Boltzmann constant, $\mathrm{A}$ is the contact area, $T$ is temperature in Kelvin scale and $A^{*}$ is the Richardson constant. For different barrier heights in a metal/semiconductor/metal junctions, the back to back Schottky contacts show rectifying behaviour where the current is dictated by the reverse biased junction. In such conditions, the current can

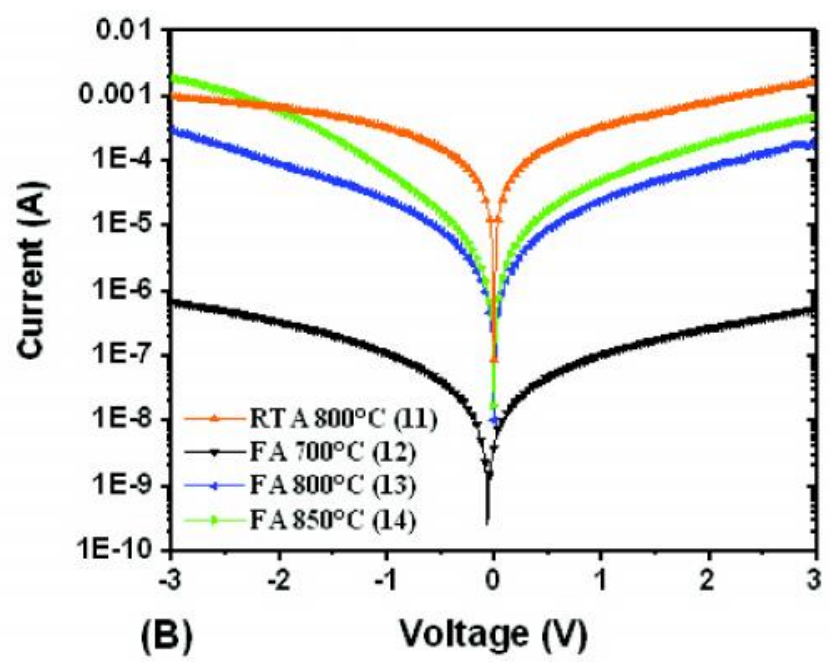

Fig. 5: (A) shows I-V curve of annealed GaAs samples for series 0 and (B) shows the I-V curve of nitrogen ion implanted GaAs samples of series 1 

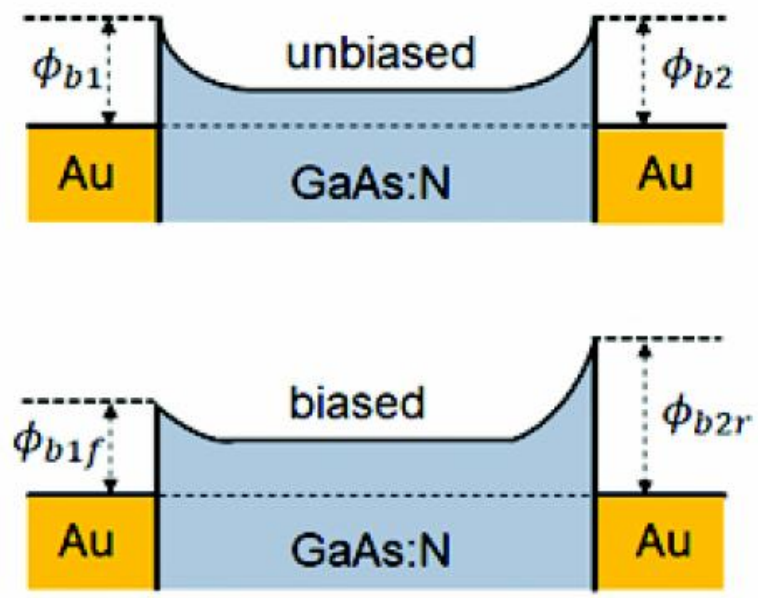

(A)

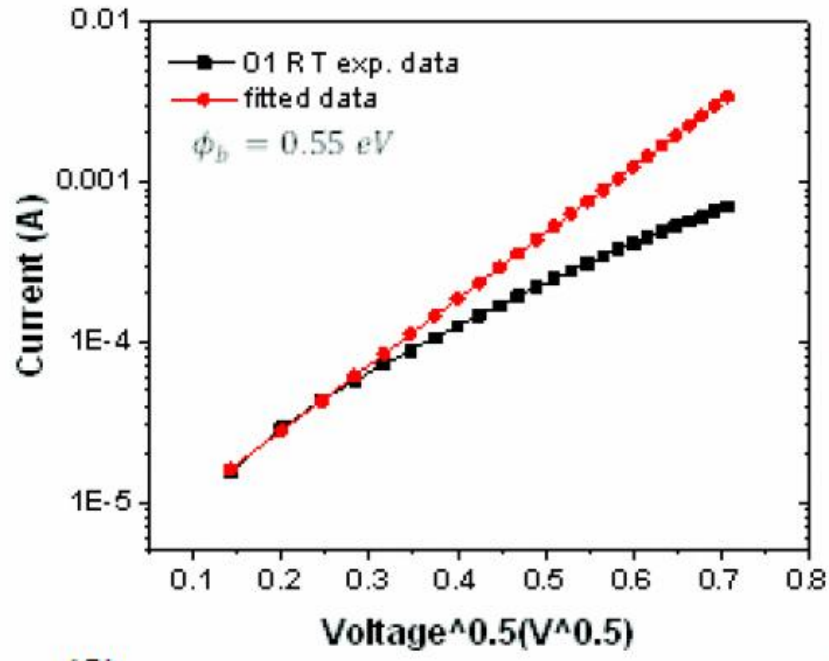

(C)
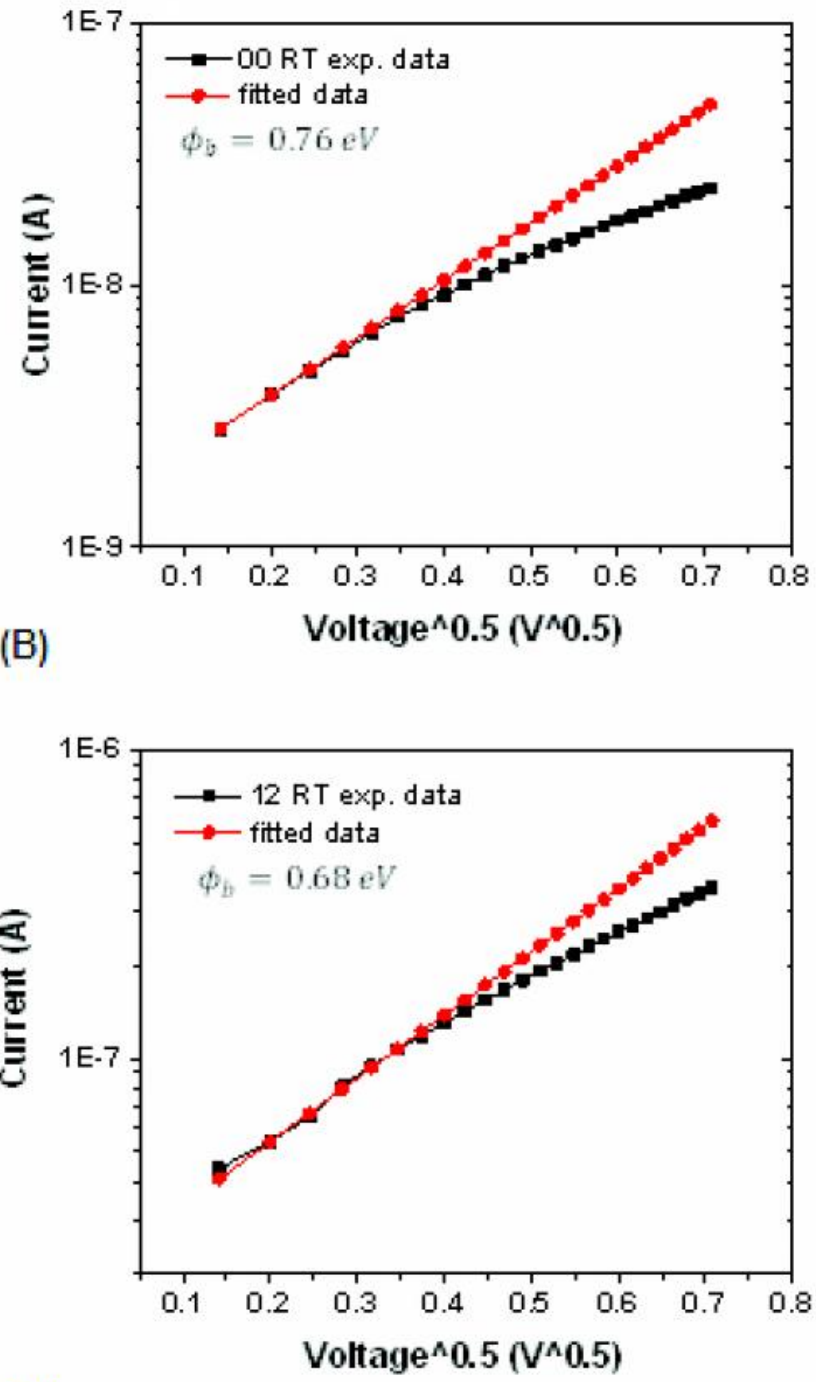

(D)

Fig. 6: (A) shows the schematic of the energy band diagram for unbiased and biased Schottky contacts and (B), (C), and (D) show room temperature I-V curve for different samples fitted with Bardeen model to calculate the barrier height

Table 3: Calculated barrier heights for different samples by Bardeen model

\begin{tabular}{lccc}
\hline $\begin{array}{l}\text { Sample series 0 } \\
\text { unimplanted }\end{array}$ & $\begin{array}{c}\text { Barrier } \\
\text { height }(\mathrm{eV})\end{array}$ & $\begin{array}{c}\text { Sample series } \\
1 \text { implanted }\end{array}$ & $\begin{array}{c}\text { Barrier height } \\
(\mathrm{eV})\end{array}$ \\
\hline $00($ as grown) & 0.76 & - & \\
$01\left(\mathrm{RTA} 800^{\circ} \mathrm{C}\right)$ & 0.55 & $11\left(\mathrm{RTA} 800^{\circ} \mathrm{C}\right)$ & 0.65 \\
$02\left(\mathrm{FA}, 700^{\circ} \mathrm{C}\right)$ & 0.75 & $12\left(\mathrm{FA}, 700^{\circ} \mathrm{C}\right)$ & 0.68 \\
$03\left(\mathrm{FA}, 800^{\circ} \mathrm{C}\right)$ & 0.58 & $13\left(\mathrm{FA}, 800^{\circ} \mathrm{C}\right)$ & 0.73 \\
\hline
\end{tabular}

be expressed by Bardeen model (Zhang and Harrell, 2003; Ranwa et al., 2014).

$$
I=I_{0} \exp \left(\frac{\beta \sqrt{V}}{k T}\right)
$$

where $I_{0}$ is the reverse saturation current, $\beta$ is the interface related parameter, $k$ is the Boltzmann constant, $V$ is the applied bias and $T$ is the absolute temperature. The $I_{0}$ is related to barrier height $\left(\Phi_{b}\right)$ by the equation:

$$
I_{0}=A A^{*} T^{2} \exp \left(\frac{-q \phi_{b}}{k T}\right)
$$

where $\mathrm{A}^{*}$ is the Richardson constant. The Richardson 


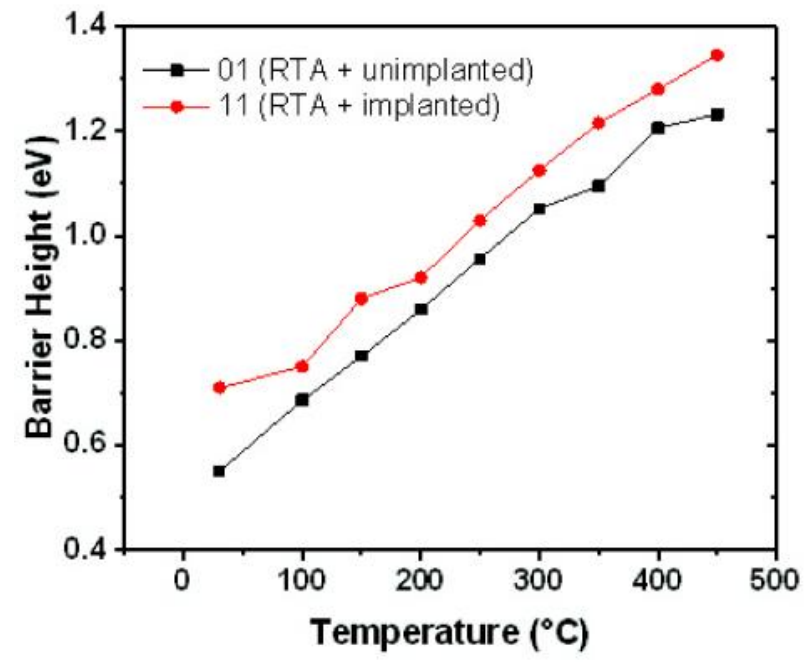

Fig. 7: Temperature dependent barrier height variation for unimplanted and implanted GaAs samples

constant for $\mathrm{p}$-GaAs is approximately $75 \mathrm{~A}-\mathrm{cm}^{-2}$ $\mathrm{K}^{-2}$. Exponential fitting is used to calculate the barrier using equation

$$
I=a \exp (b \sqrt{V})
$$

where $a$ is defined as $I_{0}$ and used to calculate the barrier height. The barrier height is calculated in low voltage regime because at higher voltages the current quickly becomes dominated by series resistance and deviates from linearity. Figure 6(A) shows the schematic representation of the energy band diagram for metal/semiconductor/metal junction under unbiased and biased conditions. Figures 6(B), (C), and (D) show the fitting according to equation 4 to calculate the barrier height of the Schottky junctions. The barrier height for as-grown GaAs sample (00) is higher compared to RTA annealed sample which is due to improved crystalline quality and reduced surface states. A similar effect is also observed in the ion implanted samples. The implantation process damages the surface and creates surface defects which increase the barrier height as seen in Fig. 6(D). Table 3 shows the barrier height of different samples calculated by Bardeen model. As-grown GaAs on $\mathrm{Si}$ shows very high barrier height $(\mathrm{S} 0.76 \mathrm{eV})$ which is due to low crystalline quality of GaAs. After RTA, the barrier height is reduced to the $0.55 \mathrm{eV}$ which is lower than the ideal value. The lower barrier height is attributed to the oxide formation during the annealing process (Sharma et al., 2007). Here we also oserved that the barrier height of the unimplanted FA @ $700^{\circ} \mathrm{C}$ GaAs sample (01) has similar value to as-grown GaAs sample (01). This implies that $\mathrm{FA}$ at $700^{\circ} \mathrm{C}$ does not improve the crystalline quality of as-grown GaAs. Sometimes at high temperature furnace annealing ( $S$ $800^{\circ} \mathrm{C}$ or above), due to arsenic eveporation from GaAs surface, increases the surface roughfness and increases the barrier height as observed in the sample (13). The ion implantation also changes the Schottky barrier height (Baranwal et al., 2009). The ion implantation induces damage at the surface which results in the higher barrier for the contacts as seen in the sample (11).

The temperature dependent study of the barrier height is done for the unimplanted and implanted GaAs samples as shown in Fig. 7. The current transport in the metal-semiconductor junction is a temperature dependent process where the electrons are transported through low barrier at low temperatures and high barrier at high temperatures. At low temperature, the carriers surmount the low barrier and transport take place through lower barrier paths. Similarly as the temperatures increases, carriers get sufficient energy to overcome the higher barrier. Therefore the barrier height increases with increasing temperature (Mahato et al., 2017).

In conclusion, sequential implantation of nitrogen ions into GaAs followed by thermal annealing has been performed. The I-V characteristic is performed to see the effect of annealing and nitrogen ion implantation in GaAs. The annealing process after ion implantation forms the GaN nanostructures and improves the crystalline quality. The experimental results show that the Schottky barrier height for metalsemiconductor junction depends on the growth parameters and post-annealing process. The increase in barrier height at $\mathrm{Au}(\mathrm{Cr}) / \mathrm{GaAs}$ contacts in implanted samples is due to ion beam damage at a surface and amorphization of GaAs.

\section{Acknowledgements}

The study is supported by the Ministry of Education and Science of the Russian Federation (Project identifier RFMEFI58414X0008) and the Department of Science and Technology, India (Project No. INT/ RUS/RMES/P-04/2014). 


\section{References}

Amine S, Assayag G B, Bonafos C, Mauduit B de, Hidriss H and Claverie A (2002) Ion beam synthesis of $\mathrm{GaN}$ precipitates in GaAs Materials Science and Engineering B93 10-14

Baranwal V, Kumar S, Pandey A C and Kanjilal D (2009) Effect of ion irradiation on current-voltage characteristic of Au/nGaN Schottky diodes J Alloys and Compounds 480962 965

Bumai Yu A, Bobuchenko D S, Akimov A N, Vlasukova LA and Filipp A R (2005) Optical properties of GaN synthesized by implantation of nitrogen ions in GaAs Vacuum 78 199122

Buzynin Yu, Shengurov V, Zvonkov B, Buzynin A, Denisov S, Baidus N, Drozdov M, Pavlov D and Yunin P (2017) GaAs/Ge/Si epitaxial substrates: Development and characteristics AIP Advances 7 015304-1-6

Chiquito A J, Amorim C A, Berengue O M, Araugo L S, Bernardo P F and Leite E R (2012) Back-to-back Schottky diodes: The generalization of the diode theory in analysis and extraction of electrical parameters of nanodevices $J$ Physics: Condensed Matter 24225303 1-7

DeLouise LA(1993) Nitridation of GaAs(110) using $\mathrm{N}^{+}$and $\mathrm{N}^{+2}$ ion beams J Vacuum Science and Technology A 11 609-614

Duncan W M and Matteson (1984) Compensation in ntype GaAs resulting from nitrogen ion implantation J Applied Physics 56 1059-1062

He L and Anderson (1991) Photoreflection and electrical characterization of Si-implanted GaAs $J$ Electronic Materials 20 359-364

Koo A, Budde F, Ruck B J, Trodhal H J, Bittar A, Preston A and Zeinert A (2006) Photoconductivity in nanocrystalline GaN and amorphous GaON J Applied Physics 9934212 $1-7$

Korolev D S, Mikhaylov A N, Belov A I, Konakov A A, Vasiliev V K, Nikolitchev D E, Surodin S I, Tetelbaum D I and Kumar M (2017) Composition and luminescence of Si and $\mathrm{SiO}_{2}$ layers co-implanted with $\mathrm{Ga}$ and $\mathrm{N}$ ions Int $J$ Nanotechnol 14 637-645

Kroemer H (1986) MBE growth of GaAs on Si: Problems and progress Mat Res Soc Symp Proc 67 3-14

Lin X W, Behar M, Maltez R, Swider W, Liliental-Weber Z and Washburn J (1995) Synthesis of GaN by N ion implantation in GaAs (100) Applied Physics Letters 67 2699-2701
Mahato S, Biswas D, Gerling LG, Voz C and Puigdollers J (2017) Analysis of temperature dependent current-voltage and capacitance-voltage characteristic of an $\mathrm{Au} / \mathrm{V} 2 \mathrm{O} 5 / \mathrm{n}-\mathrm{Si}$ Schottky diode AIP Advances 7085313 1-11

Morkoc H, Strite S, Gao G B, Lin M E, Sverdlov B and Burns M (1994) Large band gap SiC, III-V nitride, and II-VI ZnSe based semiconductor device technologies J Applied Physics 76 1363-1398

Nakamura S, Senoh M, Nagahama S, Iwasa N and Yamada T (1996) Characteristic of InGaN multiquantumwellstructure laser diodes Applied Physics Letters 68 3269-3271

Pearton S J (1989) Ion implantation for isolation of III-V semiconductors Materials Science Reports 4 313-367

Petroff P M (1986) Nucleation and growth of GaAs on Ge and the structure of antiphase boundaries $J$ Vacuum Science Technology B 4 874-877

Rajamani S, Arora K, Konakov A, Belov A, Korolev D, Nikolskaya A, Mikhaylov A, Surodin S, Kryukov R, Nikolitcchev D, Sushkov A, Pavlov D, Tetelbaum D, Kumar M and Kumar M (2018) Depp UVnarrow-band photodetector based on ion beam synthesized indium oxide quantum dots in $\mathrm{Al} 2 \mathrm{O} 3$ matrix Nanotechnology 2930

Ranwa S, Kulriya P K, Sahu V K, Kukreja L M and Kumar M (2014) Defect-free $\mathrm{ZnO}$ nanorods for low temperature hydrogen sensor applications Applied Physics Letters 105 $20131031-5$

Sharma A T, Shahnawaz, Kumar S, Katharria Y S and Kanjilal D (2007) Effect of heavy ion irradiation on the electrical characteristic of $\mathrm{Au} / \mathrm{n}-\mathrm{GaAs}$ Schottky diodes Applied Surface Science 254 459-463

Sze S M (1981) Physics of Semiconductor Devices. New York: Wiley

Weng X, Ye W, Clarke S J, Goldman R S, Rotberg V, Daniel A and Clarke R (2005) Matrix-seeded growth of nitride semiconductor nanostructures using ion beams $J$ Applied Physics 97064301 1-6

Wolk J A, Yu K M, Bourreet-Courchesne E D and Johnson E (1997) Synthesis of GaN nanocrystals by sequential ion implantation Applied Physics Letters 70 2268-2270

Zhang J and Harrell W R (2003) Analysis of the I-V characteristic of Al/4H-SiC Schottky diodes J Vacuum Science and Technology B 21 872-878. 